\title{
Surgical removal of subfoveal choroidal neovascular membranes
}

In this issue of Eye a group at Moorfields Eye Hospital report their success with the surgical removal of subfoveal choroidal neovascular membranes (CNV) in eyes which had previously undergone laser treatment for diabetic macular oedema. ${ }^{1}$ This early small series seems encouraging, with improvement in visual acuity in 2 of the 4 patients. The improvements also seemed to be maintained, with only 1 patient suffering a recurrence.

Iatrogenic $\mathrm{CNV}$ following laser photocoagulation has been described in a number of conditions: diabetic maculopathy, sickle cell disease, retinal vein occlusion, central serous retinopathy, ocular histoplasmosis, agerelated macular degeneration and sarcoidosis. ${ }^{2}$ It is thought that disruptions occur in Bruch's membrane during the laser treatment which then lead to CNV. Fortunately this is a fairly rare complication. Previous studies have indicated, in diabetes, an increased risk of CNV with small spot size, high-intensity burns and repeated applications. Further photocoagulation to destroy the CNV is associated with poor visual outcomes and high recurrence rates. ${ }^{3}$

Removal of subfoveal CNVs has been applied to many conditions where laser has devastating consequences. Its application to age-related macular degeneration has not shown the improvement first expected. ${ }^{4}$ This is primarily because the retinal pigment epithelium (RPE) in these membranes is removed with the membrane at surgery, thus leading to poor visual function post-operatively. Gass ${ }^{5}$ describes these as type 1 membranes, which have multiple ingrowth sites which cause the CNV to be predominantly below the RPE. Vitreoretinal surgeons world-wide are trying to address this with various techniques of retinal rotation and grafting. These are still under investigation and it is not clear which of these techniques will provide the best results. Type 2 membranes have a single ingrowth site and tend to proliferate above the RPE in the subsensory retinal space. More RPE cells tend to remain after surgery and better visual results are obtained. ${ }^{5}$

Certainly in disease process where type 2 membranes are present more satisfying results can be obtained with removal of $\mathrm{CNV}$ surgically, as shown in presumed ocular histoplasmosis syndrome and trauma. ${ }^{6}$ In diabetics with photocoagulation-related $\mathrm{CNV}$ which may originate from a single break in Bruch's membrane this technique would in theory give as good results. The retinal function, however, is compromised due to the underlying disease process, which may well limit the final visual result. It must not be forgotten that although these days vitrectomy is on the whole a safe procedure it is not without complications, and these must be weighed against the potential benefit to the patient.

As we move forward we may find other treatment modalities, such as photodynamic therapy, that are effective in this situation. ${ }^{7}$ For the moment the surgical removal of these membranes, from this evidence, would seem to be an option in this condition.

\section{References}

1. Duguid IGM, Rubsamen PE, le Mer Y, Luthert P, Gregor ZJ. Surgical removal of choroidal neovascular membranes after laser photocoagulation for diabetic maculopathy. Eye 2001;15:135-142.

2. Chen CJ, Urban LL, Nelson NC, et al. Surgical removal of subfoveal iatrogenic choroidal neovascular membranes. Ophthalmology 1998;105:1606-11.

3. Lewis $\mathrm{H}$, Schachat AP, Haiman MH, et al. Choroidal neovascularisation after laser photocoagulation for diabetic macular oedema. Ophthalmology 1990;97:503-10.

4. Lambert HM, Capone A Jr, Aaberg TM, et al. Surgical excision of subfoveal neovascular membranes in age related macular degeneration. Am J Ophthalmol 1992;113:257-62.

5. Gass JD. Biomicroscopic and histopathologic considerations regarding the feasibility of surgical excision of subfoveal neovascular membranes. Trans Am Ophthalmol Soc 1994;92:91-111.

6. Holekamp NM, Thomas MA, Dickinson JD, Valluri S. Surgical removal of subfoveal choroidal neovascularization in presumed ocular histoplasmosis: stability of early visual results. Ophthalmology 1997;104:22-6.

7. TAP study group. Photodynamic therapy for subfoveal choroidal neovascularisation in agerelated macular degeneration with verteporfin: one year results of 2 randomised clinical trials. TAP report 1. Arch Ophthalmol 1999;117-1329-45.
Mr Stephen Winder Department of Ophthalmology and Orthoptics

Royal Hallamshire Hospital Glossop Road Sheffield S10 2JF, UK 